\title{
Synthesis of Antimony Sulphoiodide by CVD and its Characterization
}

\author{
Harish K. Dubey*1, L. P. Deshmukh ${ }^{1}$, D. E. Kshirsagar ${ }^{2}$, Vijay S. Jadhav ${ }^{3}$, Madhuri Sharon ${ }^{4}$ \\ and Maheshwar Sharon ${ }^{4}$ \\ ${ }^{1}$ Department of Physics, Solapur University, Solapur, M.S., India, ${ }^{2}$ Nanotechnology Research Centre, \\ Birla College, Kalyan, M.S., India, ${ }^{3}$ Department of Physics, University of Pune, Pune, M. S., India, \\ ${ }^{4}$ NSNR Center for Nanotechnology \& Bionanoterchnology, SICES degree College, Ambernath.
}

Email: harish.nano@gmail.com

\begin{abstract}
Antimony Sulphoiodide is most widely studied compound in group V-VI-VII family due to its large number of properties. Varoius methods of synthesis have been reported. We are the first to report synthesis of shiny SbSI crystals by the Chemical Vapor Deposition (CVD) technique using powder of Antimony, Sulphur and Iodine as the starting material. Needle shaped thin crystals of SbSI were found grown vertically on the walls of the quartz tube. Characterizations of the sample were done using different techniques such as powder X-ray diffraction (XRD), scanning electron microscopy (SEM) and energy dispersive $X$-ray analysis (EDAX). The charcteristcs peaks in Raman scattering plots ( 0 $500 \mathrm{~cm}^{-1}$ ) match with the reported results. The compound exibits high resitivity at room temperature in the order of $10^{7} \Omega$-cm and dielectric constant in the order of $10^{3}$ measured at $1 \mathrm{KHz}$.
\end{abstract}

Keywords: SbSI, CVD, XRD, SEM, EDAX

\section{Introduction}

Synthesis of $\mathrm{A}^{\mathrm{V}} \mathrm{B}^{\mathrm{VI}} \mathrm{C}^{\mathrm{VII}}$ (Where $\mathrm{A}=\mathrm{Sb}, \mathrm{Bi} ; \mathrm{B}=\mathrm{S}$, Se, Te and $\mathrm{C}=\mathrm{I}, \mathrm{Cl}, \mathrm{Br}$ ) compounds has been achieved ${ }^{2}$. Antimony sulphoiodide (SbSI) is one of the ternary chalcogenide of this group having unique properties such as rare combination of strongly coupled photoconductive ${ }^{1,2}$, semiconductive ${ }^{1,11}$, pyroelectric ${ }^{4,5}$, and ferroelectric ${ }^{3}$ properties, which have been subjects of much interest. Furthermore the crystal exhibits large electro-optical and electro-mechanical properties too ${ }^{6}$. The SbSI compound crystallizes in the orthorhombic system with space group $\mathrm{D}^{16}{ }_{2 \mathrm{~h}}$ above $20^{\circ} \mathrm{C}$ and with the space group $\mathrm{C}^{9}{ }_{2 \mathrm{v}}$ at temperature below that ${ }^{7}$. Due to these properties it is an attractive and suitable material for thermal imaging $8,9,10-13$, light modulator, ${ }^{8,14}$, ferroelectric field effect transistor (FeFET) ${ }^{15,16}$, gas sensors ${ }^{17}$, piezoelectric elements used in certain types of electromechanical transducers $8,18,19,20$ temperature auto stabilized nonlinear dielectric elements (TANDEL) ${ }^{21,22}$, time-controlling devices $8,9,23$ etc. The SbSI is taken into consideration as a valuable material for photonic crystals ${ }^{24,25}$.

Being a promising material with potential applications, SbSI was synthesized by many researchers in a variety of ways. For the first time SbSI was synthesized by Donges ${ }^{26}$ in 1950 . Since then a lot of techniques have been used to produce SbSI crystals. Nittsche et al. ${ }^{2}$ employed the melt growth route with the Bridgman-Stockbarger technique to produce parallel bundles of fibrous crystals. Kern ${ }^{6}$ and Belyaev et al. ${ }^{27}$ have used vapor phase growth technique to produce millimeter

\section{*Corresponding author}


size crystals in a vacuum between $360{ }^{\circ} \mathrm{C}$ and $410{ }^{\circ} \mathrm{C}$. At the same time, hydrothermal growth method ${ }^{28,29}$ has also been used to synthesize SbSI. Popolitov and Litvin ${ }^{8}$ conducted experiments under hydrothermal conditions at $250-300{ }^{\circ} \mathrm{C}$, and $400-600$ ata from $\mathrm{H}_{2} \mathrm{~S}$ solution at $\mathrm{pH}$ 5-6. Rau and Rabenau $^{29}$ used a quartz ampoule with an external pressure of 2400 ata and a filling 9M HI solution at $250-490{ }^{0} \mathrm{C}$. Nassau et al. ${ }^{30}$ used a modified flux technique by using excess $\mathrm{SbI}_{3}$ as the solvent and circum venting the inherent growth anisotropy to grow large SbSI crystals. Palaniappan et al. ${ }^{31}$ obtained large column like crystals from vapor phase at lower temperature of $320{ }^{\circ} \mathrm{C}$. Recently Nowak et $\mathrm{al}^{33}$ adopted sonochemical method for the direct preparation of nano crystalline SbSI.

In most of the reports $\mathrm{Sb}_{2} \mathrm{~S}_{3}$ and $\mathrm{SbI}_{3}{ }^{32}$ are used as the starting material to derive SbSI with the following chemical equation:

(i) $\mathrm{Sb}_{2} \mathrm{~S}_{3}+\mathrm{SbI}_{3}=3 \mathrm{SbSI}$

(ii) $\mathrm{SbI}_{3}+2 \mathrm{Sb}+3 \mathrm{~S}=3 \mathrm{SbSI}$

Use of the elements $\mathrm{Sb}, \mathrm{S}$ and I were avoided with a view that $\mathrm{Sb}, \mathrm{S}$ and I unite exothermally generating a huge vapor pressure which may lead to explosion. In this paper we are, for the first time, reporting the synthesis of SbSI by Chemical Vapor Deposition (CVD)technique using Sb, S and I as the starting material with a simple chemical equation:

(iii) $\mathrm{Sb}+\mathrm{S}+\mathrm{I}=\mathrm{SbSI}$

\section{Experimental Methods}

\section{Synthesis of the material}

A CVD setup consisting of a high temperature furnace with temperature control unit, a quartz tube as the reaction chamber, $\mathrm{Ar}$ as the carrier gas and a suitable arrangement to control the gas flow was fabricated (Fig. 1).

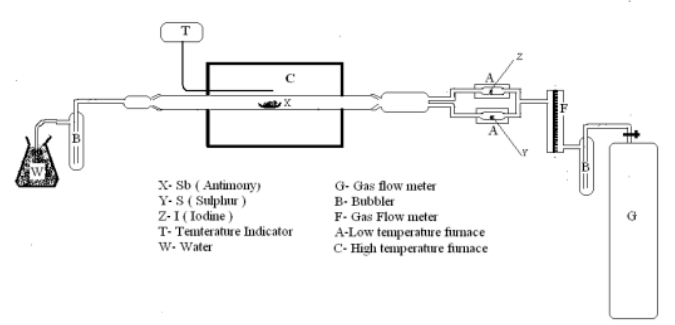

Fig-1 Schematic diagram of CVD setup used for synthesis of SbSI

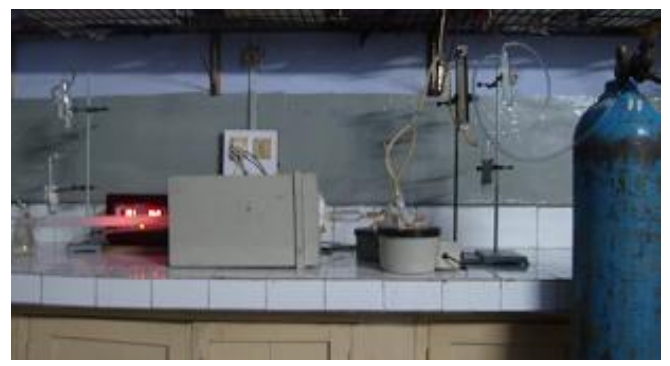

Figure -2 Photograph of experimental setup used for the reaction

Known quantity of powered $\mathrm{Sb}$ was taken into a quartz boat and was placed inside the quartz tube, Sulphur and Iodine were placed in the two separate tubes of similar dimensions having separate openings, outside the high temperature zone of the furnace. The quartz tube had two inlet and one outlet openings and was inserted in high temperature zone of horizontal furnace. The two tubes were placed in two separate heating mantles (not shown in the figure -1). To both the tubes Ar gas was supplied from one end; whereas the other end of both the tubes was connected to the quartz reaction tube. A flow meter was connected between the tubes and the gas cylinder to control the flow rate of the gas entering into the tubes. Along with the flow meter two bubblers were also introduced at the inlet and outlet of the quartz tube. The gas coming out of the reaction tube was immersed into a container filled with water.The actual experimental setup shown in the figure 2. Initially the quartz tube was flushed for 5 to 6 min with Ar, so that fully inert atmosphere is created in the reaction chamber. No gas flow was allowed there-after till the furnace attained $650{ }^{\circ} \mathrm{C}$ temperature. Then the heating mantles were switched $\mathrm{ON}$, so that by the time 
main furnace attains $650{ }^{\circ} \mathrm{C}$, tubes containing Sulphur and Iodine attain the temperature little more than their meting points so that they produce the vapor of the $\mathrm{S}$ and I. These vapors were then carried to the quartz tube along with the flow of the Ar gas. The reaction time was standardized to 6 hrs. so that the whole amount of the $\mathrm{S}$ and I get transported to $\mathrm{Sb}$ chamber. The product was in the form of a large number of thin needle shaped SbSI crystals accumulated vertically on the walls of the quartz tube in the low temperature zone and a polycrstalline bulk in the boat. The crystals so obtained were regrounded and presses into pallets for further studies.

\section{Characterization}

The obtained needles were cleaned with $\mathrm{CS}_{2}$ and $\mathrm{CCl}_{4}$ and grinded to powder. SbSI crystals were characterized by powder X-ray diffraction (XRD), scanning electron microscopy (SEM), energy dispersive X-ray analysis (EDAX) and Raman scattering.

\section{Electrical Propterties}

Two probe setup was develped to find the reistance of the pallet in the temerature range of $40{ }^{\circ} \mathrm{C}$ to $250{ }^{\circ} \mathrm{C}$. To menatin the inert atmosphre Ar gas was passed contineously through the chamber containing the sample. To find the dielectric constant, the SbSI pallet was sanwitched batween two parallel plates and its capcitance was measured at room temperature $\left(30{ }^{\circ} \mathrm{C}\right)$. Aplab L-C-R meter was used to find the capacitance at $1 \mathrm{KHz}$.

\section{Results and Discissions}

Though the reaction amongst these three elements took place in the high temperature zone of the quartz tube, a large number of thin needles shaped SbSI crystals accumulated vertically on the walls of the quartz tube in the low temperature zone. Few agglomerated crystals were seen sticking on the wall of the tube (Fig-4). However, there was some residual material remaining in the boat too. The residue in the boat was found to be solidified form of Sb. The method is found suitable for the synthesis of SbSI and can be used to synthesise other group V-VI-VII elements but the yield of this method is as low as $29.25 \%$ (Table-1). The loss in of the total weight of the constituent materials and the product with the outgoing vapors is observed. This is due to the high temperature and large reaction time with a significant flow rate of carrier gas to tarnsport the Sulfur and Iodine in the reaction Chamber containing Antimony.

Table-1 Percentage yield of CVD method in the synthesis of SbSI

\begin{tabular}{|c|c|c|c|c|c|c|}
\hline $\begin{array}{c}\text { Sample } \\
\text { no. }\end{array}$ & $\begin{array}{c}\text { Mass of } \\
\mathrm{Sb}\end{array}$ & $\begin{array}{c}\text { Mass of } \\
\mathrm{S}\end{array}$ & Mass of I & $\begin{array}{c}\text { Mass of } \\
\text { Sb+S+I }\end{array}$ & $\begin{array}{c}\text { Mass of produced } \\
\text { SbSI }\end{array}$ & \multirow{2}{*}{$\begin{array}{c}\text { Yield ( } \\
\%)\end{array}$} \\
& & & & & residue + needles & \\
\hline $\mathrm{L}-1$ & $1 \mathrm{gm}$ & $1.0 \mathrm{gm}$ & $1.0 \mathrm{gm}$ & $3 \mathrm{gm}$ & $0.960 \mathrm{gm}$ & 32.00 \\
\hline $\mathrm{L}-2$ & $1.0 \mathrm{gm}$ & $1.0 \mathrm{gm}$ & $1.5 \mathrm{gm}$ & $3.5 \mathrm{gm}$ & $0.820 \mathrm{gm}$ & 23.43 \\
\hline L-3 & $1.0 \mathrm{gm}$ & $1.0 \mathrm{gm}$ & $2.0 \mathrm{gm}$ & $4.0 \mathrm{gm}$ & $0.990 \mathrm{gm}$ & 14.75 \\
\hline L-4 & $1.0 \mathrm{gm}$ & $1.5 \mathrm{gm}$ & $1.0 \mathrm{gm}$ & $3.5 \mathrm{gm}$ & $0.830 \mathrm{gm}$ & 23.71 \\
\hline L-5 & $1.0 \mathrm{gm}$ & $1.5 \mathrm{gm}$ & $1.5 \mathrm{gm}$ & $4.0 \mathrm{gm}$ & $0.980 \mathrm{gm}$ & 24.50 \\
\hline L-6 & $1.0 \mathrm{gm}$ & $1.5 \mathrm{gm}$ & $2.0 \mathrm{gm}$ & $4.5 \mathrm{gm}$ & $1.040 \mathrm{gm}$ & 22.22 \\
\hline L-7 & $3.0 \mathrm{gm}$ & $4.0 \mathrm{gm}$ & $2.0 \mathrm{gm}$ & $9.0 \mathrm{gm}$ & $2.970 \mathrm{gm}$ & 33.00 \\
\hline L-8 & $3.0 \mathrm{gm}$ & $4.0 \mathrm{gm}$ & $3.0 \mathrm{gm}$ & $10 \mathrm{gm}$ & $2.380 \mathrm{gm}$ & 23.80 \\
\hline
\end{tabular}

- 113 - 
J. Nepal Chem. Soc., vol. 30, 2012

\begin{tabular}{|c|c|c|c|c|c|c|} 
L-9 & $7.5 \mathrm{gm}$ & $10.0 \mathrm{gm}$ & $10.0 \mathrm{gm}$ & $27.5 \mathrm{gm}$ & $6.050 \mathrm{gm}$ & 22.00 \\
\hline L-11 & $3.0 \mathrm{gm}$ & $2.0 \mathrm{gm}$ & $3.0 \mathrm{gm}$ & $8 \mathrm{gm}$ & $2.720 \mathrm{gm}$ & 34.00 \\
\hline L-12 & $3.0 \mathrm{gm}$ & $2.0 \mathrm{gm}$ & $4.0 \mathrm{gm}$ & $9 \mathrm{gm}$ & $2.690 \mathrm{gm}$ & 29.89 \\
\hline L-13 & $4.0 \mathrm{gm}$ & $3.0 \mathrm{gm}$ & $2.0 \mathrm{gm}$ & $9 \mathrm{gm}$ & $3.100 \mathrm{gm}$ & 34.44 \\
\hline L-14 & $4.0 \mathrm{gm}$ & $3.0 \mathrm{gm}$ & $3.0 \mathrm{gm}$ & $10 \mathrm{gm}$ & $3.410 \mathrm{gm}$ & 34.10 \\
\hline L-15 & $4.0 \mathrm{gm}$ & $3.0 \mathrm{gm}$ & $4.0 \mathrm{gm}$ & $11 \mathrm{gm}$ & $3.730 \mathrm{gm}$ & 33.91 \\
\hline L-16 & $4.0 \mathrm{gm}$ & $4.0 \mathrm{gm}$ & $2.0 \mathrm{gm}$ & $10 \mathrm{gm}$ & $4.200 \mathrm{gm}$ & 42.00 \\
\hline L-18 & $4.0 \mathrm{gm}$ & $4.0 \mathrm{gm}$ & $4.0 \mathrm{gm}$ & $12 \mathrm{gm}$ & $4.200 \mathrm{gm}$ & 35.00 \\
\hline \multicolumn{7}{c}{ Average Percentage yield $=\mathbf{2 9 . 2 5} \%$} \\
\hline
\end{tabular}

\section{XRD Analysis}

The XRD pattern of the reaction product (Fig. 3) shows well defined, sharp peaks indicating high purity and well crystallized structure. All the diffraction peaks can be indexed to be a pure orthorhombic phase for SbSI with the cell constants $\mathrm{a}=8.516{ }^{0} \mathrm{~A}, \mathrm{~b}=10.124{ }^{0} \mathrm{~A}, \mathrm{c}=4.122{ }^{0} \mathrm{~A}$. The identification was done using the PCW computer program. In each XRD pattern, the reflections can be indexed to those of the corresponding pure phases, and all the lattice parameters are very close to the reported data ${ }^{34}$. The intensities and positions of the peaks are in good agreement with literature values for $\mathrm{SbSI}^{34}$

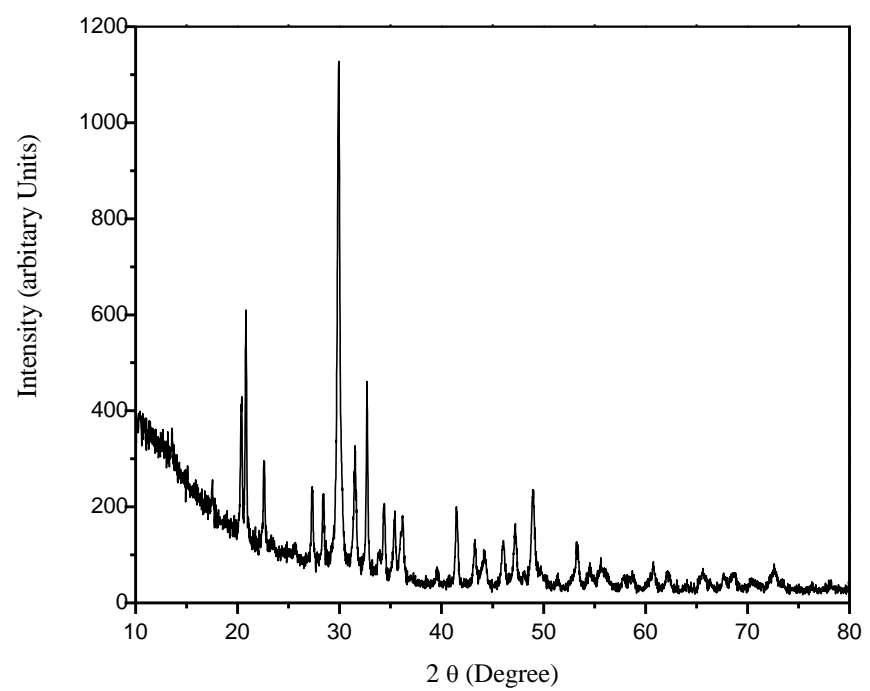

Figure-3. XRD of SbSI at room temperature

\section{Energy Dispersive X $($ EDAX $)$}

The characteristic EDAX peaks for antimony, sulfur and iodide were observed and confirmed with an elemental atomic percentage of 29.53: 31.00: $39.47 \mathrm{for} \mathrm{Sb}, \mathrm{S}$ and I averaged over the SbSI. So, it indicates within the experimental error a Stoichiometric SbSI. 


\section{SEM Analysis}

The photograph (Fig.-4 and 5) and the SEM images (Fig.-6 and 7) of the sample reveal its predominant needle like morphology.

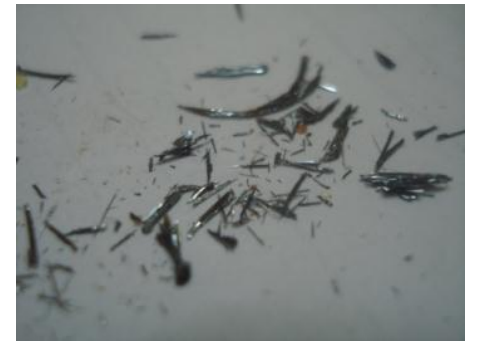

Fig-4 Photograph of the SbSI samples

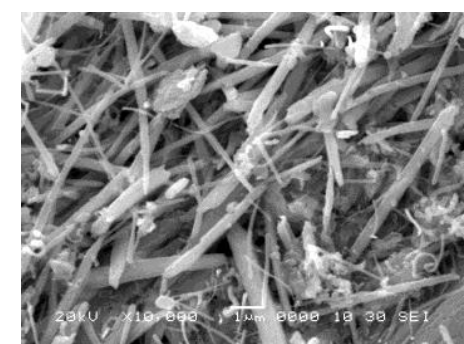

Fig-6 SEM image of SbSI crystals

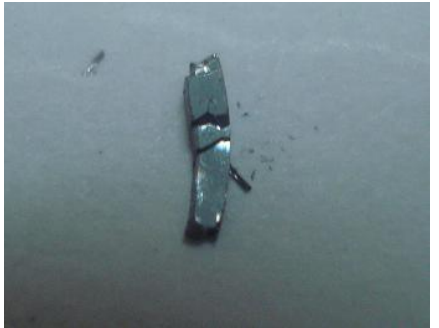

Fig-5 Photograph of the SbSI single crystal

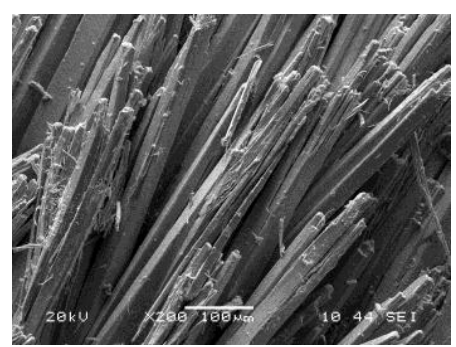

Fig-7 SEM image of SbSI poly crystalline bulk

\section{Raman Scattering Data}

The Raman spectra of powdered SbSI observed at room temperature matches with the reported data ${ }^{35}$. The reported Raman shift was in the range of $40-200 \mathrm{~cm}^{-1}$ where as the Raman spectra shown in fig-8 ranges from 0 to $500 \mathrm{~cm}^{-1}$ with characteristics peaks at 70, 81, 90, 118, 151, 226 and $331 \mathrm{~cm}^{-}$ 1 . Therefore we are reporting additional peaks in the range of 200 to $500 \mathrm{~cm}^{-1}$.

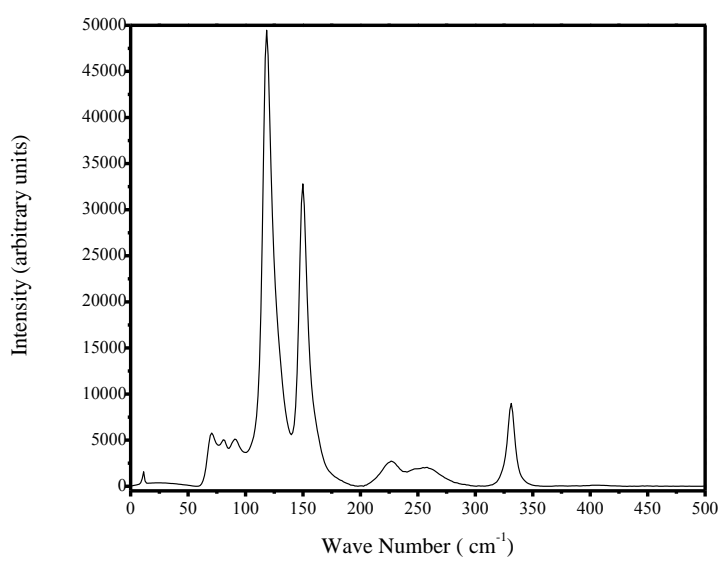

Fig-8 Raman Spectrum of SbSI

- 115 - 
The observations made shows that the CVD method can be a novel method to prepare fine needles of SbSI, but it does not seem to be suitable for fabricating big single crystals.

It seems that SbSI belongs to the family of many solid materials ${ }^{33}$ that naturally grow into polycrystalline structure and this habit is determined by the highly anisotropic bonding in the crystallographic structure. The observed rod type morphology of the product is possibly due to the inherent chain type structure and growth habit of SbSI.

\section{Resistivity and Dielectric Constant}

The Resistance vs Temperature measuremts indicate semiconducting behaviour shown by the material (fig-9). The electrical resitivity of the sample was calculated to be $5 \times 10^{7} \Omega$ - $\mathrm{cm}$ whereas the dielectric constant was found to 10232 at $30^{\circ} \mathrm{C}$.

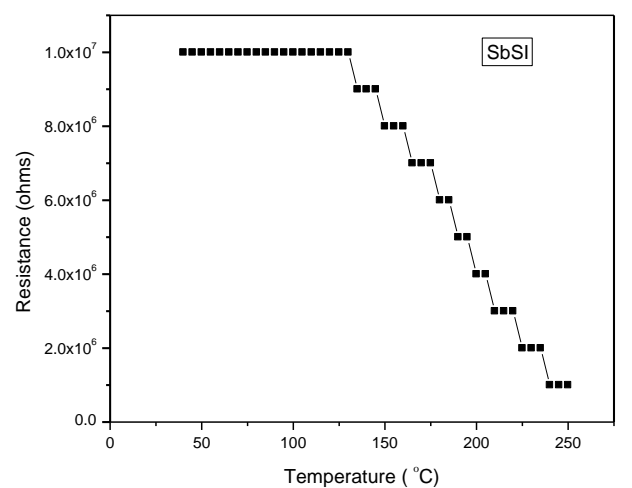

Fig-9 Resistance varisation of SbSI with Temparature

\section{Conclusion}

The compound was prepared essentially quantitatively from the constituents (the elements: antimony, sulphur and iodine) using Chemical Vapor Deposition. Characterization of the SbSI was confirmed using various different techniques, such as powder X-ray diffraction (XRD), scanning electron microscopy (SEM) and energy dispersive X-ray analysis (EDAX). The charcteristcs peaks in Raman scattering plots $\left(0-500 \mathrm{~cm}^{-1}\right)$ match with the reported results. The compound exibits high resitivity at room temperature in the order of $10^{7} \Omega$-cm and dielectric constant in the order of $10^{3}$ measured at $1 \mathrm{KHz}$.The chemical Vapor deposition method can be a novel method to prepare fine needles of SbSI, but it does not seem to be suitable for big single crystals. The loss of the constituent materials with the outgoing vapors is also observed with the measurement of the total weight the constituent materials and the product. This method can be a suitable method for the development of uniform thin films of SbSI as seen on the walls the quartz tube.

\section{References}

1. V. M. Fridkin, I. I. Groshik, V. A. Lakhovizkaya, M. P. Mikhailov and V. N. Nosov, Applied Physics Letters, 1967, 10, 354-356.

2. R. Nitsche, W.J. Merz, J. Phys. Chem. Solids, 1960, 13, 154-155.

3. E. Fattuzzo, G. Harbeke, W Merz, R. Nitsche,Physical review, 1962, 6, 2036-2037

4. K. Hamano, T. Nakamura, Y. Ishibashi, Y. Ooyane, J. Phys. Soc. Jpn., 1965, 20, 1886.

\section{- 116 -}


5. Kiyoyusu Imai, Shuji Kawada Journal of the Physical Society of Japan,1966, 21, 1855-1860

6. D. Berlin court, Hans Jaffe, W.J.Merz, R. Nitsche, Applied Physics letters , 1964, 4, 61-63

7. Atsushi Kikuchi, Yoshio Oka, Etsuro Sawaguchi, Journal of the Physical Society of Japan,1967, 23, 337-354

8. E.I. Gerzanich, V.A. Lyakhovitskaya, V.M. Fridkin, B.A. Popovkin, in: E. Kaldis (Ed.), Current Topics in Materials Science, 1982, 10, 55-190.

9. $\quad$ E.I. Gerzanich,V.M. Fridkin, Segnetoelektriki tipa A5B6C7, Nauka, Moskwa, 1982

10. J.-F. Li, D. Viehland, A.S. Bhalla, L.E. Cross, J. Appl. Phys.,1992, 71 (5), 2106-2112.

11. S. Kotru, W. Liu, R.K. Pandey, in: ISAF 2000, Proceedings of the 2000 12th IEEE International Symposium on Applications of Ferroelectrics (IEEE Cat. No.0 0CH37076), IEEE, Part vol. 1, Piscataway, NJ, 2001, pp. 231-234.

12. X. Song, M.A. Hannan, S. Kotru, R.K. Pandey, in: Proceedings of the 10th European Meeting on Ferroelectricity, 2003, p. 316.

13. R.K. Pandey, S. Kotru, S. Xiuyu, D. Donnelly, American Physical Society, March Meeting 2004, March 22-26, 2004, Palais des Congres de Montreal, Montreal, Quebec, Canada, MEETING ID: MAR04, abstract P21.006.

14. A.Kh. Zeinally, A.M. Mamedov, Optiko-Mekhanicheskaya Promyshlennost 1975, 42, 72-73.

15. Y. Higuma, Y. Matsui, M. Okuyama, Y. Hamakowa, T. Nakagawa, Jpn. J. Appl. Phys. 17 (Suppl. $17-$ 1) ,1977 209-214.

16. Shyam Shruti, Sushma Kotru, and R. K. Pandey, Integrated Ferroelectrics, 2002, 48, 263-269

17. V.V. Betsa, Y.V. Popik, Fizika Tverdogo Tela,1977, 19 (1), 278-280

18. A.A. Grekov, S.P. Danilova, P.L. Zaks, V.V. Kulieva, L.A. Rubanov,L.N. Syrkin, N.P. Chekhunova, A.M. Elgard, Akusticheskii Zurnal, 1973,19 (4) 622-623.

19. Yu.S. Nakonechnyi, I.D. Turyanitsa, Fizika Tverdogo Tela , 1974, 16 (8) , 2365-2368

20. G.K. Arakelyan, V.A. Lyakhovitskaya, V.D. Spitsina, V.M. Fremd, Seismicheskie Pribory: Instrumental'Naye Sredstva Seismicheskikh Nablyudenii,1980. 13, 63-67

21. G.C. Alexandrakis, K.M. Rittenmyer, P.S. Dubbelday, J. Acoust. Soc. Am. , 1986, 80 (Suppl. 1), S69

22. K.M. Rittenmyer, G.C. Alexandrakis, P.S. Dubbelday, J. Acoust. Soc. Am., 1988, 84 (6) , 2002-2006.

23. A.A. Grekov, N.A. Korchagina, E.D. Rogach, Prib. Tekh. Eksp. ,197922 (4), 262-26

24. V.A. Kanaev, Y. Cao, M.A. Fiddy, Opt. Eng, 2005, . 44 (9), 095201-1-095201-11.

25. J. Ballato, A. Ballato, Waves Random Complex Media.2005, 15 (1), 113-118.

26. E. Dönges, Z. Anorg. Allg. Chem. (1950), 263 , 112-132.

27. L.M. Belyaev, V.A. Lyakhovitskaya, G.B. Netesov, M.V. Mokhosoev, S.M. Aleikhina, Izv. Akad. Nauk SSSR,Neorg. Mater., 1965, 1, 2178.

28. V.I. Popolitov, B.N. Litvin, Kristallografiya 1968, 13 , 571.

29. H. Rau, A. Rabenau, SolidState Commun., 1967, 5, 331.

30. K. Nassau, J.W. Shiever, M. Kowalchik, J. Crystal , J. Crystal Growth,1970, 7

31. L. Palaniappan,M. Shanmugham, F. D. Gnanam and P. Ramaswamy, J.of. Crystal growth, 1986, 79, $517-521$

32. Z. Dziuba, J. Crystal Growth , 1976, 35 (3), 340-342

33. M. Nowak, P. Szpetlich, L. Bober, J. Szala, G. Moskal, D. Stroz, Ultrasonics Sonochemistry,2008, $15,709-716$

34. Antimony Sulfide Iodide, JCPDS-International Centre for Diffraction Data, PCPDFWIN v. 2.1, Card File No. 74 -0149, 2000.

35. A. V. Gomonnai, L.M. Voynarovych,A. M. Solomon,Yu. M. Azhniuk, A.A.Kikineshi, V. P. Pinzenik, M. Kis-Varga, L. Daroczy, V. V. Lopushansky, Material Research Bulletin 2003, 38, 1767-1772 